\title{
Naturologia na UNISUL: 20 anos de conquistas e desafios
}

\section{Naturology in UNISUL: 20 years of achievements and challenges}

\author{
Nat. Drd. Daniel Maurício de Oliveira Rodrigues \\ Nat. MSc. Janete Aparecida Gaspar Machado
}

DOI: $10.19177 / \mathrm{cntc} . \mathrm{v} 7 \mathrm{e} 1220189-11$

$\mathrm{E}$ m meados da década de 90, a Universidade do Sul de Santa Catarina (UNISUL), Campus de Palhoça - SC, e o Instituto São Lucas de Naturologia Aplicada (ISLUNA) formalizaram o projeto de implantação do curso de Naturologia Aplicada, segundo parâmetros já existentes em diversos países.

$\mathrm{O}$ investimento pioneiro, atendendo aos parâmetros norteadores iniciais, previra uma formação profissional que, referendada pelos conhecimentos das áreas da saúde, arte e educação, disponibilizaria , na matriz curricular, uma abordagem educativa e integrativa do processo vida-saúde-doença. Naquele contexto, e ante as restrições expressas por coordenadores de outros cursos, o projeto submeteu-se aos contornos de curso de pós-graduação e, nessa configuração, formou três turmas. A instituição alcançou, por essa via, os méritos de experiência educativa bem sucedida, mensurada nos índices de procura pelo referido curso de pós-graduação.

Semelhante resultado motivou a Unisul a criar, em 1998, o primeiro bacharelado de Naturologia Aplicada, no Brasil, em cuja proposta curricular articulavam-se as ciências exatas, humanas, biológicas e da saúde. Esse inusitado projeto de graduação trouxe, para a academia, a profissionalização, o debate e a produção de novos modos de cuidado em saúde e de novas formas de organizar a prestação dos serviços, com envolvimento, inclusive, do sistema educacional, com que o curso assegurava, ao Naturólogo, também, a qualificação como educador.

A graduação em Naturologia, no Brasil, já soma vinte anos. Nesse período, tem conquistado espaço na área da saúde, apresentando-se como sistema atuante e em evolução contínua, visando à ampliação das possibilidades de qualificação tanto do perfil profissional a que se propõe, quanto da própria atenção básica à saúde. Com ações orientadas à consolidação de uma profissão singular, edifica-se, permanentemente, na demonstração da coerência de seus pressupostos acadêmicos , de sua atuação prática, dos trabalhos científicos de pesquisa que produz, de sua presença e intervenção nos espaços em que lhe compete atuar.

A análise dessa caminhada de 20 anos, e de suas conquistas, enfatiza os números do desempenho da graduação em Naturologia enquanto núcleo agregador de interessados nessa formação profissional específica. Hoje, na Unisul, seus discentes matriculados somam cerca de 200 (duzentos) estudantes das mais diversas regiões do Brasil e de outros países. $O$ corpo docente é constituído por 30 (trinta) professores, dos quais 8 (oito) são naturólogos egressos do próprio curso da Unisul e, muitos deles, já mestres ou doutores em diversas áreas do conhecimento.

Circundadas pela exigência de progresso e de aperfeiçoamento, as principais alterações curriculares consolidaram-se na gestão do primeiro coorde- 
nador naturólogo (Nat. Dr. Fernando Hellmann). Foram mantidas ou ampliadas pelas gestões posteriores das Professoras Dra. Luana Maribele Wedekin, Nat. Drd. Patrícia Kozuchovski Daré e Nat. Dr ${ }^{\mathrm{d}}$. Daniel Maurício de Oliveira Rodrigues, atual gestão.

Indicativos consideráveis de sua evolução, esses reordenamentos das diretrizes e objetivos do curso, a partir de 2009, delinearam a reformulação do Projeto Pedagógico do Curso (PPC), destinando-o à formação acadêmica do profissional para um modelo de atenção à saúde, não convencional, mas sujeito ao que é considerado indispensável pela Organização Mundial de Saúde - OMS, bem como em sintonia com os propósitos das Políticas Nacionais de Práticas Integrativas e Complementares (PNPIC) e as orientações das políticas nacionais educacionais e trabalhistas.

Sob essa atual configuração, o Curso de Naturologia, passou a assistir as expectativas do Sistema Único de Saúde, em conformidade com os principais fundamentos naturológicos reunidos nos conceitos de Relação de Interagência e de Visão Multidimensional do Ser Humano, os quais vêm exaustivamente elucidados nas publicações do Curso, notadamente no livro Referências em Naturologia - Um sistema terapêutico de cuidado em saúde (2018).

A partir de um perfil profissional extensivo, sugerido na primeira versão do Curso, a Naturologia, hoje, redefiniu-se singularmente em uma proposta atualizada para a formação estrita em saúde, em que se evidencia o respeito às prerrogativas da saúde integral e de sua prática clínica. Dos currículos anteriores, imersos em aspectos biológicos e psicológicos do processo vida-saúde-doença, o PPC atual fomenta seus pressupostos teóricos na consonância com aspectos sociais, ambientais e espirituais, nas teorias das Racionalidades em Saúde propostas por Luz, das Racionalidades advindas do oriente (Ayurveda e Terapêutica Tradicional Chinesa), da Cosmologia Xamânica, da Terapia Comunitária, das Terapias Mente-corpo, além das Terapias já bem estudadas nos PPC anteriores.

Nessa reestruturação, a coordenação do curso exercida por profissionais com formação em Naturologia tornou-se relevante para mobilizar as políticas de inserção do profissional no mercado de trabalho, priorizando a implementação de recursos aptos a dar visibilidade ao Naturólogo, quer junto aos espaços públicos de prestação de serviço, quer junto às demais categorias de trabalhadores da saúde, quer junto aos espaços de reivindicação.

É o que se ilustra na menção às especificidades atuais do estágio curricular, repensado para atender, também, essas demandas específicas. Até então, limitado ao espaço da Clínica Escola da Unisul, expandiu-se para os espaços públicos de outras instituições, principalmente aqueles voltados para o SUS (Unidades Básicas de Saúde, Policlínicas, Centro de Atenção Psicossocial, Hospitais), além de escolas, creches, asilos, orfanatos, estâncias hidrominerais, centro de atenção à pessoa idosa, times profissionais de esportes, empresas, dentre outros.

Outro setor basilar, amplamente qualificado e amparado, é o da pesquisa orientada pela Naturologia. Os Trabalhos de Conclusão de Curso (TCC) dos graduandos, devidamente conduzidos, efetivam-se nos artigos científicos publicados em revistas indexadas nacionais e internacionais.

Igualmente agregada ao campo da pesquisa, ganha magnitude a criação de uma revista científica na área da Naturologia e Terapias Complementares, "Cadernos de Naturologia e Terapias Complementares", que hoje já está indexada em bases, como a Biblioteca Virtual de Saúde (BVS-BIREME). Além da publicação da revista impressa e online semestralmente, o curso é o mediador de 7 (sete) publicações referenciais, em livros, dos quais (4 (quatro) livros versam sobre Naturologia; os outros 3 (três), sobre Medicalização da Vida, Geoterapia e Termalismo.

Essa produção de material científico representa contribuição indispensável ao trabalho de padronização, organização e investigação da eficácia das práticas integrativas e complementares no Brasil. E, justamente por essa razão, igualmente, atua em favor do lugar da Naturologia junto à OMS e junto às políticas nacionais de atenção básica à saúde, especialmente no que se refere à Política Nacional de Práticas Integrativas e Complementares e a sua inclusão no SUS.

A infraestrutura também tornou-se objeto de atenção e de cuidado, com vistas à exploração de seu 
potencial. Recentemente, o horto medicinal foi revitalizado; os laboratórios e a Clínica Escola (antiga casa da colina) receberam reformas funcionais. Para potencializar os recursos humanos da Clínica Escola de Naturologia, uma naturóloga já graduada (Fernanda Sartor Zarth) passou a exercer, de modo assertivo, as atribuições administrativas relativas a esse espaço de multissignificação exponencial entre o Interagente e a Naturologia.

Nas ações de extensão universitária da Unisul, o curso é considerado um dos principais proponentes de eventos no Campus, oportunizando o contexto adequado à discussão de temas emergentes nos campos da saúde, política e educação. Destacam-se as semanas acadêmicas, que acontecem no final de cada semestre, nas quais são apresentados os TCC, a Mostra de Experiências de Estágios, palestras, mesas redondas e atividades culturais e artísticas. Além dos eventos, o curso de Naturologia compartilha, com o público externo e acadêmico, inúmeros cursos de extensão para qualificação pessoal e profissional.

No decurso de seus 20 anos de atuação, a graduação em Naturologia é autora de projetos de extensão de excelência, como é o exemplo do Termalismo Social e Crenoterapia no Estado de Santa Catarina. Trata-se de projeto que recebeu fomento do governo federal para realizar um diagnóstico situacional, capacitar profissionais de saúde e do turismo e produzir materiais informativos. Desenvolvido em parceria com a Secretaria Estadual de Saúde, o projeto cingiu 17 (dezessete) cidades com águas termais e minerais, atingindo resultado im- prescindível ao fortalecimento das Práticas Integrativas e Complementares no Estado.

As políticas de divulgação (aprimoramento das mídias sociais e acolhida aos interessados e calouros), incluindo a atenção à demanda por bolsas de estudo e as ações para reduzir a evasão (alteração da alocação de docentes e a oferta de Unidades de Aprendizagem mais práticas desde as primeiras fases do curso), fazem da Naturologia, hoje, um dos cursos com o maior número de acadêmicos da Unisul, expressando sua consolidação junto ao panorama de cursos da instituição.

Os êxitos já alcançados dão suporte a projetos maiores, inextricavelmente suscitados na trajetória do curso de Naturologia, ao longo de seus 20 anos de atuação inconteste na área da saúde. Nesse horizonte de desafios, previsivelmente necessárias, alinham-se duas deliberações intrépidas: uma nova reformulação do PPC, para atender diretrizes curriculares em sintonia com os apelos de internacionalização do curso, e o apoio político institucional às demandas pela regulamentação da profissão.

Desdobram-se da urgência de credenciais e ordenamentos jurídicos para integração do Naturólogo ao rol de profissões da área da saúde. E são, de fato, compromissos da graduação em Naturologia, de seus Naturólogos, mas, também, de órgãos e instâncias políticas correlacionados aos interesses sociais, bem como do público motivado por essas vertentes transdisciplinares e interdisciplinares de cuidado à saúde, que estão na origem das políticas de Práticas Integrativas e Complementares no Brasil. 